\title{
Abordagem cirúrgica inédita para denervação acetabular em cães ${ }^{1}$
}

\author{
Cássio R.A. Ferrigno ${ }^{2 *}$, Alexandre Schmaedecke² e Vanessa C.M. Ferraz ${ }^{3}$
}

\begin{abstract}
Ferrigno C.R.A., Schmaedecke A. \& Ferraz V.C.M. 2007. [A new surgical approach to acetabular denervation in dogs.] Abordagem cirúrgica inédita para denervação acetabular em cães. Pesquisa Veterinária Brasileira 27(1):61-63. Departamento de Cirurgia do Hospital Veterinário, Faculdade de Medicina Veterinária e Zootecnia, Universidade de São Paulo, Av. Prof. Orlando Marques de Paiva 87, São Paulo, SP 05508-900, Brazil. E-mail: cassioaf@usp.br

The purpose of this study is to demonstrate a new surgical approach for the selective denervation of the sensitive fibers of the acetabular periosteum, for the treatment of hip dysplasia in dogs, conducted in 189 joints.The surgical approach of the cranial and dorso-lateral regions of the acetabular joint in dogs, by moon-shaped incision of approximately $3 \mathrm{~cm}$ in extension, starting from the greater trocanter of the femur, in direction of the ileum body. After dorsal opening of the middle gluteal muscle, the insertion of the deep gluteal muscle is inserted for the access to the mentioned regions. With the help of a curette, the periosteum of the cranial and dorso-lateral acetabular margin was removed until the bone cortex was exposed, in all patients. In all animals, the approach was possible, both in the cranial as well as in the caudal faces for the access and curettage of the acetabulum, with the technique described, with a skin incision of about $3.2 \mathrm{~cm}$. The curettage of the cranial portion of the acetabulum was, in all cases, realized without the visualization of the bone, but of easy achievement and without intercurrences of nervous or muscular injuries. In all the approaches, it was possible to visualize the articular capsule of the coxo-femoral joint, and in none of the animals, this structure was incised for a technique mistake. The surgical approach described in the present study is feasible for this kind of surgical procedure in dogs, promoting adequate access, with minimal invasion and with no complications of any nature.
\end{abstract}

INDEX TERMS: Hip dysplasia, surgical technique, peripheral nerves, dogs, surgery.

RESUMO.- Este artigo tem por objetivo demonstrar nova abordagem cirúrgica para denervação seletiva das fibras sensitivas do periósteo acetabular, para tratamento da displasia coxo femoral em cães, conduzidas em 189 articulações. Para tanto, é descrita abordagem da região cranial e dorso-lateral do acetábulo de cães por incisão em forma de meia lua de aproximadamente de três centímetros de extensão, iniciando trocânter maior do fềmur e em direção ao corpo do ílio. Após rebatimento dorsal do músculo glúteo médio, secciona-se parcialmente a inserção do m. glúteo profundo para acesso às regiões citadas. Com auxílio de cureta foi removido, em todos os pacientes, periósteo na margem acetabular

\footnotetext{
${ }^{1}$ Recebido em 30 de outubro de 2006.

Aceito para publicação em 8 de novembro de 2006.

${ }^{2}$ Departamento de Cirurgia do Hospital Veterinário, Faculdade de Medicina Veterinária e Zootecnia (FMVZ), Universidade de São Paulo (USP), Av, Prof. Orlando Marques de Paiva 87, São Paulo, SP 05508-900. *Autor para correspondência: cassioaf@usp.br

${ }^{3}$ Pós-Graduando, Depto Cirurgia, FMVZ, USP.
}

cranial e dorso lateral, até a exposição da cortical óssea. Em todos os animais foi possível a abordagem, tanto da face cranial como também acesso para a curetagem da face dorsal do acetábulo, com a técnica descrita, com incisão de pele de aproximadamente $3,2 \mathrm{~cm}$. A curetagem da porção cranial do acetábulo foi, em todos os casos realizados, sem visualização do osso, mas de fácil confecção e sem intercorrências de lesão de nervos ou músculos. Em todas as abordagens foi possível visualizar a cápsula articular da articulação coxo femoral, e em nenhum dos animais esta estrutura foi incisada por erro de técnica. Conclui-se que a abordagem cirúrgica descrita no presente trabalho é factível para este tipo de procedimento cirúrgico em cães, promovendo acesso adequado, com mínima invasão e sem complicações de qualquer natureza.

TERMOS DE INDEXAÇÃO: Displasia coxo-femoral, técnica cirúrgica, nervos periféricos, cães, cirurgia.

\section{INTRODUÇÃO}

A displasia coxofemoral de cães foi definida como uma doença biomecânica, representada pela disparidade entre a massa 
muscular primária e o rápido crescimento ósseo (Alexander 1992).

Os tratamentos cirúrgicos como, pectinectomia, osteotomias corretivas, artroplastia das bordas acetabulares, osteotomia pélvica tripla e outras técnicas similares ainda mostram resultados controversos (Matis 2000, Bollinger et al. 2002, Kinzel et al. 2002).

A literatura é clara em afirmar que o tratamento cirúrgico que apresenta os melhores resultados é a alo-artroplastia, ou a substituição das partes articulares por uma prótese metálica, a despeito dos seus custos e complicações pós-cirúrgicas inerentes à técnica operatória (Olmstead 1995, Matis 2000, SumnerSmith 2000. Kinzel et al. 2002).

Nos últimos anos, tratamentos alternativos menos cruentos vêm sendo pesquisados. Em estudo inovador, Kinzel \& Küpper (1997) relataram a técnica de desenervação da cápsula articular coxofemoral, que, segundo os autores, trata-se de neurectomia seletiva de fibras sensitivas da cápsula articular, com intuitos puramente analgésicos.

Para tanto os autores utilizaram abordagem cirúrgica para o Íleo lateral, com incisão entre três a cinco centímetros iniciando no trocânter maior e seguindo em linha reta até a crista do íleo. O osso então é alcançado pela divulsão romba entre os músculos bíceps femoral, glúteo médio e tensor da fáscia lata (Kinzel et al. 2002).

Abordagem semelhante foi relatada para a correção de fraturas de íleo (Kinzel \& Küpper 1997). Além disto, estes preconizavam a elevação do músculo glúteo profundo para visualização da região do íleo próximo a borda acetabular cranial.

Quando há a necessidade da exposição da região cranial do acetábulo, sem a osteotomia do trocânter maior, as técnicas descritas por Archibald et al.(1953) e Brown \& Rosen (1971) ainda hoje são utilizadas, e ambas preconizam incisão de pele em direção dorso ventral iniciando-se na borda cranial do íleo e descendo até o meio do fêmur, margeando a sua superfície cranial.

Wadsworth \& Henry (1974) descreveram abordagem similar as anteriores, mas preconizaram a elevação periosteal, e 0 afastamento cranial do músculo glúteo profundo, expondo assim a superfície dorsal do acetábulo.

Método mais cruento foi descrito por Gorman (1957), onde o autor estudou a abordagem tanto da margem cranial, como também a margem dorsal e caudal do acetábulo após a osteotomia do trocânter maior e rebatimento dos músculos glúteo superficial, médio e profundo cranialmente.

Com o intuito de verificar a possibilidade de realizar a técnica de denervação modificada por Ferrigno et al. (2004) com abordagem menos cruenta que as já descritas na literatura, estudou-se no presente trabalho uma nova proposição de abordagem para a superfície cranial e dorsal do acetábulo em 189 articulações.

\section{MATERIAL E MÉTODOS}

Foram utilizados 189 cães de diferentes raças, sexos e pesando entre 17 e $67 \mathrm{~kg}$ de peso, com diagnóstico clínico e radiográfico de displasia coxo femoral que foram encaminhados para a cirurgia de denervação pelo método modificado de Ferrigno et al. (2004) uni ou bilateralmente dependendo do acometimento da moléstia, no período de janeiro de 2001 a março de 2006, e em todos os animais foi realizada a nova abordagem cirúrgica, objetivo deste estudo.

Para tanto, após raspagem dos pelos, e realização de protocolos anestésicos mais apropriados a cada paciente, sendo em que nenhum deles foram realizadas anestesias epidurais, os animais foram colocados em decúbito lateral.

Foram então realizados os preparos rotineiros de campo operatório, seguidos de incisão cutânea, em forma de meia lua de aproximadamente de três centímetros de extensão, iniciando trocânter maior do fêmur e em direção ao corpo do ílio. A seguir, foi efetuada a divulsão dos tecidos subjacentes, a localização, da fáscia entre o músculo glúteo médio e o músculo tensor da fáscia lata, a qual foi incisada e rebatido o músculo glúteo médio dorsalmente expondo então o músculo glúteo profundo.

Após a elevação periosteal do músculo glúteo profundo de sua ligação com o corpo do ílio, através de diérese da inserção mais caudal ao corpo do íleo com bisturi, o músculo foi rebatido dorsalmente utilizando afastador de Homman em forma de alavanca apoiado margem dorsal do ílio, expondo então a região cranial da borda acetabular.

Então com cureta foi removido, em todos os pacientes, todo o periósteo na margem acetabular cranial, até a exposição da cortical óssea (Ferrigno et al. 2004).

Posteriormente, a face dorsal do acetábulo foi também tratada pelo mesmo método descrito acima, mas para tanto a cureta foi introduzida entre o osso e o músculo glúteo profundo em direção caudal, sem a visualização da borda acetabular.

Finalmente, a região curetada foi lavada com solução fisiológica. A aproximação da fáscia entre o músculo glúteo médio e o músculo tensor da fáscia lata foi realizada com fio de PDS 2-0 em pontos simples contínuos e a pele suturada com náilon 2-0.

\section{RESULTADOS}

Em todos os animais foi possível a abordagem, tanto da face cranial como também acesso para a curetagem da face dorsal do acetábulo, com a técnica descrita, com incisão de pele de aproximadamente $3,2 \mathrm{~cm}$.

A visualização da borda cranial do acetábulo e corpo do íleo foi possível e de boa qualidade em todos os casos.

Não houve intercorrências como lesão de nervos ou vasos de grande calibre.

Em 102 abordagens $(53,96 \%)$ foram expostas parte do feixe vásculo nervoso íleo circunflexo profundo na borda cranial da incisão entre o músculo glúteo médio e o músculo tensor da fáscia lata, mas esta estrutura não interferiu com a amplitude da abordagem.

A curetagem da porção cranial do acetábulo foi, em todos os casos realizados, sem visualização do osso, mas de fácil confecção e sem intercorrências de lesão de nervos ou músculos.

Em todas as abordagens foi possível visualizar a cápsula articular da articulação coxo femoral, e em nenhum dos animais esta estrutura foi incisada por erro de técnica.

Em nenhum dos casos houve hemorragia significante, e a síntese das estruturas musculares, subcutâneo e pele foram realizadas facilmente.

\section{DISCUSSÃO}

A abordagem realizada no presente trabalho permitiu, com a incisão por diérese da inserção do músculo glúteo profundo, 
melhor visibilização das estruturas ósseas e articulares, em comparação as abordagens antes preconizadas por Hohn \& James (1966) e Kinzel et al. (2002), pois estes autores preconizam a divulsão romba do músculo, causando lesão muscular maior, além de um campo de visão que não permite maior acesso as porções mais caudais do íleo, como a cápsula articular e a margem acetabular cranial e dorsal.

Para tanto anteriormente diferentes abordagens de maior porte foram preconizadas como as de Archibald et al. (1953), Brown \& Rosen (1971) e Wadsworth \& Henry (1974) onde eram realizadas osteotomia do trocânter maior, o que em comparação a abordagem estuda, permitia grande acesso a esta região, mas com complexidade, maior tempo e lesão de tecidos ósseos e musculares. No entanto a abordagem realizada no trabalho mostrou que é possível o acesso e curetagem da região dorsal do acetábulo, sem no entanto necessitar da osteotomia do trocânter maior.

Apesar desta constatação apenas o procedimento de curetagem da região dorsal do acetábulo é possível com o acesso estudado, e correções de fraturas ou luxações coxo femorais devem seguir as abordagens anteriormente citadas, pois não foi necessário a visualização e manipulação da região dorsal do acetábulo para a curetagem, que era realizada deslizando a cureta caudalmente apoiada na lamina óssea, elevando assim o músculo glúteo profundo, portanto permitindo apenas a palpação da região e não a observação da mesma.

Gorman (1957) descreveu técnica que associavam as abordagens para a região cranial do íleo e a borda dorsal acetabular, para tanto a osteotomia do trocânter maior e rebatimento, após diérese das inserções dos músculos, glúteo superficial, médio e profundo cranialmente. Apesar de ser abordagem necessária para reparo de fraturas, no caso da desperiostização do íleo a técnica descrita é mais aconselhada, devido ao menor tamanho da incisão, e menor lesão tecidual.

\section{CONCLUSÃO}

Após a realização de 189 procedimentos de denervação periosteal da região cranial e dorsal do íleo e acetábulo conclui-se que a técnica de abordagem cirúrgica descrita no presente trabalho é factível de ser realizada para este tipo de procedimento cirúrgico em cães.

\section{REFERÊNCIAS}

Alexander J.W. 1992. The pathogenesis of canine hip dysplasia. Vet. Clin. North Am. 22(3):503-513.

Archibald J., Brown N.M., Nasti E. \&. Medway W.M. 1953. Open reduction for correction of coxofemoral dislocations. Vet. Med., Small Anim. Pract. 48:273-275.

Bollinger C., DeCamp C.E., Stajich M., Flo G.L., Martinez S.A., Bennet R.L. \& Bedchuck T. 2002. Gait analysis of dogs with dysplasia treated with gold bead implantation acupuncture. VCOT 15:116-122.

Brown S.G. \& Rosen H. 1971. Craniolateral approach to the canine hip: a modified Watson-Jones approach. J. Am. Anim Hosp Assoc. 159(9):11171122.

Ferrigno C.R.A., Dávila R.S., Yamamoto E.Y., Yazbek K.V.B. \& Ferraz V.C.M. 2004. Estudo da técnica de denervação da cápsula articular coxofemoral no tratamento da dor em cães com displasia coxofemoral: resultados preliminares. Braz. J. Vet. Res. Anim. Sci. 41(Supl.):169-170.

Gorman H.A. 1957. A new prosthetic hip joint; experiences in its use in the dog, and its probable application to man. Mil-Med. 121(2):91-93

Hohn R.B. \& James J.M. 1996. Lateral approach to the canine ilium. Anim. Hosp. 2:111. (Cit. Piermattel \& Johnson 2004)

Kinzel S. \& Küpper W. 1997. Operationstechnik und klinische Erfahrungen zur Hüftgelenksdenervation beim Hund. Prakt. Tierarzt 27:26-29.

Kinzel S., Hein S., von Scheven C. \& Küpper W. 2002. 10 Jahre Erfahrung mit der Denervation der Hüftgelenkkapsel zur Therapie der Hüftgelenkdysplasie und Arthrose des Hundes. Tierärztl. Wochenschr. 115:5356 .

Matis U. 2000. Hip dysplasia therapy. Scient. Proc. WSVA World Congress, Amsterdam, p.383-384.

Olmstead M.L. 1995. Canine cemented total hip replacements: state of the art. J. Small Anim. Pract. 36:395-399.

Piermattel D.L. \& Johnson K.A. 2004. An Atlas of Surgical Approaches to the Bones and Joints of the Dog and Cat. $4^{\text {th }}$ ed. Elsevier, Amsterdean, p.290-295.

Sumner-Smith G. 2000. Hip dysplasia. Scient. Proc. WSVA World Congress, Amsterdam. p.382-383.

Wadsworth P.L. \& Henry W.B. 1974. Dorsal surgical approach to acetabular fractures in the dog. J. Am. Med. Assoc. 165(10):908-910. 